\title{
Optimal therapy for patients with hepatocellular carcinoma and resistance or intolerance to sorafenib: challenges and solutions
}

This article was published in the following Dove Press journal:

Journal of Hepatocellular Carcinoma

8 November 2017

Number of times this article has been viewed

\author{
Emily M Ray \\ Hanna K Sanoff \\ Division of Hematology/Oncology, \\ University of North Carolina, Chapel \\ Hill, NC, USA
}

\begin{abstract}
The only US Food and Drug Administration (FDA)-approved first-line systemic therapy for hepatocellular carcinoma (HCC) is sorafenib; however, resistance or intolerance to sorafenib is unfortunately common. In this review, we briefly describe systemic therapies that can be considered for patients with $\mathrm{HCC}$ who show resistance or intolerance to sorafenib. For all patients with HCC who need systemic therapy, we strongly advocate for participation in clinical trials. Cytotoxic chemotherapy plays a minor role in the treatment of advanced HCC, with some data supporting the use of FOLFOX (infusional fluorouracil, leucovorin, and oxaliplatin) and GEMOX (gemcitabine-oxaliplatin). Multi-target kinase inhibitors such as lenvantinib and regorafenib have recently met their primary endpoints as first- and second-line therapy, respectively, with regorafenib now representing the only FDA-approved drug for second-line treatment of HCC. Other targeted therapies remain under investigation, but results so far have not significantly changed clinical practice. Immunotherapy is an interesting area of research in the treatment of HCC with preclinical and early clinical data demonstrating exciting results; thus numerous investigational studies are currently focusing on immunotherapy in the treatment of HCC. While systemic treatment options in HCC remain a challenge for providers, in this review, we summarize the current literature and highlight areas of progress with respect to the treatment of patients with $\mathrm{HCC}$ and resistance or intolerance to sorafenib.
\end{abstract}

Keywords: liver cancer, chemotherapy, immunotherapy

\section{Introduction}

Hepatocellular carcinoma (HCC) is a major cause of morbidity and mortality in the US and around the world. The incidence of HCC is increasing, with an estimated 782,000 new cases per year worldwide. ${ }^{1}$ In the US, where there are approximately 4 million people living with chronic infection of hepatitis $\mathrm{C}$ virus (HCV) and where the annual incidence rate of HCC among patients with $\mathrm{HCV}$-related cirrhosis is $2 \%-8 \%$, we can expect an increase in the annual incidence rate of $\mathrm{HCC}$ despite effective $\mathrm{HCV}$ treatment. ${ }^{2,3}$ In addition, recent data have shown that metabolic disorders, such as nonalcoholic fatty liver disease (NAFLD), account for more number of cases of HCC than any other risk factor including HCV infection, which is primarily due to the high prevalence of NAFLD in the overall population. ${ }^{4}$ Sixty to seventy percent of the patients present with advanced disease which is not appropriate for surgical resection or liver-directed therapies. ${ }^{5}$ Therefore, for such patients, systemic therapy is highly recommended. ${ }^{6}$
Correspondence: Hanna K Sanoff Division of Hematology/Oncology, University of North Carolina, 170 Manning Drive, Chapel Hill, NC 27599, USA

Email Hanna_sanoff@med.unc.edu 
The only US FDA-approved first-line systemic therapy for HCC is sorafenib, which is a multi-targeted oral small molecule tyrosine kinase inhibitor (TKI) that inhibits Raf kinase, the vascular endothelial growth factor receptors (VEGFRs) $1-3$ and the platelet-derived growth factor receptor- $\beta$ (PDGFR- $\beta$ ). Sorafenib was approved on the basis of results from the Phase III SHARP trial which demonstrated an overall survival (OS) benefit of sorafenib compared with best supportive care alone (10.7 months versus 7.9 months; hazard ratio $[\mathrm{HR}]=0.69 ; 95 \%$ confidence interval $[\mathrm{CI}]=0.55-0.87$; $P<0.001))^{7}$ The most common severe sorafenib-related toxicity was found to be diarrhea (grade 3 in $8 \%$ of the patients; grade 4 in $<1 \%$ of the patients), hand-foot syndrome (grade 3 in $8 \%$ of the patients), and fatigue (grade 3 in $8 \%$ of the patients; grade 4 in $1 \%$ of the patients). Most frequent reasons for discontinuation of sorafenib were found to be gastrointestinal events (6\%), fatigue (5\%), and liver dysfunction (5\%). ${ }^{7}$

Despite the observed survival benefit from sorafenib, resistance to sorafenib is very common. Primary resistance to sorafenib was identified in about a quarter of patients in the SHARP trial; however, $43 \%$ of the patients' disease was found to be in control, which lasted for more days $(\geq 28)$ beyond the first scan showing response or stable disease. ${ }^{7}$ Resistance to sorafenib is thought to be mediated by overexpression of epidermal growth factor receptor (EGFR) by the tumor including other downstream signaling molecules. ${ }^{8}$ Acquired resistance to sorafenib involves several mechanisms, such as abnormal activation of PI3K/Akt and JAK-STAT pathways, the activation of hypoxia-inducible pathways to allow progression of malignant cells despite hypoxia, and epithelial-mesenchymal transition which enhances tumor cell migration and invasion. ${ }^{8}$

While many patients with sorafenib intolerance or resistance are unable to to receive additional therapy because of the advanced nature of their disease and cirrhosis, those with a good performance status often seek additional options. Because of comorbid cirrhosis and the general chemotherapyrefractory nature of HCC, finding second and third line treatment options can be challenging. Herein, we will describe systemic therapies that can be considered in patients with sorafenib refractory HCC. A summary of agents studied for use in HCC is provided in Table 1, with the most promising therapeutic options and their outcomes shown in Table 2.

\section{Clinical trials}

Given the generally dismal outcomes in HCC, patients with HCC who are not candidates for resection or transplantation should be considered for clinical trials whenever possible. There is a growing understanding of the signaling pathways
Table I Therapeutic agents studied for treatment of advanced hepatocellular carcinoma

\section{Cytotoxic chemotherapy}

Cisplatin/interferon alpha-2b/doxorubicin/fluorouracil (PIAF)

Doxorubicin

Fluorouracil/leucovorin/oxaliplatin (FOLFOX)

Gemcitabine/oxaliplatin

Hormone therapies

Lanreotide

Megesterol

Octreotide

Tamoxifen

\begin{tabular}{l} 
Molecularly targeted therapies \\
\hline Multi-targeted agents \\
Lenvatinib \\
Regorafenib \\
Sorafenib \\
Mesenchymal-epithelial transition factor (MET) inhibitors \\
Tivantinib \\
Anti-vascular endothelial growth factor (VEGF) agents \\
Axitinib \\
Bevacizumab \\
Ramucirumab \\
Sunitinib \\
Anti-epidermal growth factor receptor (EGFR) agents \\
Cetuximab \\
Erlotinib \\
Other targeted therapies \\
Everolimus (mTOR inhibitor) \\
Brivanib (fibroblast growth factor receptor TKI) \\
\hline Immunotherapy \\
\hline Durvalumab (PD-LI inhibitor) \\
Nivolumab (PD-I inhibitor) \\
Pembrolizumab (PD-I inhibitor) \\
Tremelimumab (CTLA-4 inhibitor) \\
\hline
\end{tabular}

Abbreviation: TKI, tyrosine kinase inhibitor.

Table 2 Therapeutic options for first- and second-line treatment of advanced hepatocellular carcinoma

\begin{tabular}{lll}
\hline $\begin{array}{l}\text { First-line } \\
\text { therapy }\end{array}$ & $\begin{array}{l}\text { Median PFS } \\
\text { (months) }\end{array}$ & $\begin{array}{l}\text { Median OS } \\
\text { (months) }\end{array}$ \\
\hline Sorafenib $^{38}$ & 3.7 & 12.3 \\
Lenvatinib $^{38}$ & 7.4 & 13.6 \\
\hline Second-line & $\begin{array}{l}\text { Median PFS } \\
\text { (months) }\end{array}$ & $\begin{array}{l}\text { Median OS } \\
\text { (months) }\end{array}$ \\
therapy & 3.1 & 10.6 \\
\hline Regorafenib $^{37}$ & 2.9 & Not met in study \\
FOLFOX $^{13}$ & 5 & 12 \\
\hline GemOx & &
\end{tabular}

Abbreviations: OS, overall survival; PFS, progression-free survival.

(eg, Ras/Raf/MAPK, WNT- $\beta$-catenin, EGFR, insulin-like growth factor receptor, AKT-mTOR, Notch, and Hedgehog) that drive hepatic carcinogenesis, and their components represent potential molecular targets for therapy in HCC (Table 3). ${ }^{9}$ Somatic genomic profiling using multiplex assays may be a 
Table 3 Phase II and III studies of targeted therapies in hepatocellular carcinoma

\begin{tabular}{|c|c|c|c|c|}
\hline Agent(s) studied & $\begin{array}{l}\text { Mechanism of action of } \\
\text { agent studied }\end{array}$ & $\begin{array}{l}\text { Year } \\
\text { published }\end{array}$ & Primary endpoint & Results \\
\hline \multicolumn{5}{|l|}{ Advanced disease } \\
\hline \multicolumn{5}{|l|}{ First-line therapy } \\
\hline Sorafenib versus placebo ${ }^{7}$ & Multi-targeted TKI & 2008 & Overall survival & I 0.7 versus 7.9 months $(P<0.00 \mathrm{I})$ \\
\hline Sunitinib versus sorafenib ${ }^{31}$ & $\begin{array}{l}\text { Multi-targeted TKI, VEGFR } \\
\text { inhibitor }\end{array}$ & 2013 & $\begin{array}{l}\text { Overall survival *terminated early } \\
\text { for futility and safety reasons }\end{array}$ & 7.9 versus 10.2 months $(P=0.00 \mid 4)$ \\
\hline Brivanib versus sorafenib ${ }^{60}$ & VEGFR and FGFR inhibitor & 2013 & Overall survival & $\begin{array}{l}9.5 \text { versus } 9.9 \text { months }(\mathrm{HR}=\mathrm{I} .06 \text {; } \\
95 \% \mathrm{Cl}=0.93-\mathrm{I} .22)\end{array}$ \\
\hline $\begin{array}{l}\text { Sorafenib+erlotinib versus } \\
\text { sorafenib }\end{array}$ & EGFR TKI & 2015 & Overall survival & 9.5 versus 8.5 months $(P=0.408)$ \\
\hline Linifanib versus sorafenib ${ }^{32}$ & VEGFR and PDGFR TKI & 2015 & Overall survival & $\begin{array}{l}9.1 \text { versus } 9.8 \text { months }(\mathrm{HR}=0.92 \text {, } \\
95 \% \mathrm{Cl}=0.896-\mathrm{I} .22 \mathrm{I})\end{array}$ \\
\hline $\begin{array}{l}\text { Lenvatinib versus } \\
\text { sorafenib }^{40}\end{array}$ & Multi-targeted TKI & 2017 & Overall survival, noninferiority & $\begin{array}{l}\mathrm{I} 3.6 \text { versus } \mathrm{I} 2.3 \text { months } \\
(\mathrm{HR}=0.92,95 \% \mathrm{Cl}=0.79-\mathrm{I} .06)\end{array}$ \\
\hline \multicolumn{5}{|l|}{ Second-line therapy } \\
\hline Brivanib versus placebo ${ }^{35}$ & VEGFR and FGFR inhibitor & 2013 & Overall survival & 9.4 versus 8.2 months $(P=0.3307)$ \\
\hline $\begin{array}{l}\text { Ramucirumab versus } \\
\text { placebo }^{34}\end{array}$ & $\begin{array}{l}\text { VEGFR inhibitor, monoclonal } \\
\text { antibody }\end{array}$ & 2015 & Overall survival & 9.2 versus 7.6 months $(P=0.14)$ \\
\hline Tivantinib versus placebo ${ }^{37}$ & MET inhibitor & 2017 & Overall survival & 8.4 versus 9.1 months $(P=0.81)$ \\
\hline $\begin{array}{l}\text { Regorafenib versus } \\
\text { placebo }^{39}\end{array}$ & Multi-targeted TKI & 2017 & Overall survival & 10.6 versus 7.8 months $(P<0.000 \mathrm{I})$ \\
\hline Nivolumab $^{58}$ & PD-I immune checkpoint inhibitor & 2017 & Objective response rate & $20 \%(95 \% \mathrm{Cl}=\mathrm{I} 5-26)$ \\
\hline
\end{tabular}

Abbreviations: $\mathrm{Cl}$, confidence interval; EGFR, epidermal growth factor receptor; FGFR, fibroblast growth factor receptor; MET, mesenchymal-epithelial transition factor; PD-I, programmed cell death-I; PDGFR, platelet-derived growth factor receptor; TACE, transarterial chemoembolization; TKI, tyrosine kinase inhibitor; VEGFR, vascular endothelial growth factor receptor.

way to enrich clinical care by detecting actionable mutations, though the percentage of patients with HCC with actionable mutations in a recent prospective clinical sequencing study was less than $10 \% .{ }^{10}$ Creating tools to match patients with actionable mutations with available clinical trials is an area of ongoing investigation, and the number of "actionable" mutations is expected to increase as basic and clinical sciences increasingly focus on precision oncology. ${ }^{11}$ For all of our patients with HCC who need systemic therapy, we strongly advocate for participation in clinical trials.

\section{Cytotoxic chemotherapy}

Cytotoxic chemotherapy plays a minor role in the treatment of advanced HCC. Doxorubin was long considered the most effective chemotherapeutic agent in the treatment of advanced HCC, but recent evidence refutes any significant benefit. Alliance/CALGB 80802 compared sorafenib alone to sorafenib in combination with doxorubicin in 346 patients with advanced HCC. Patients treated with combination therapy experienced more toxicity and inferior OS (9.3 months vs 10.5 months for sorafenib) or progression-free survival (PFS). ${ }^{12}$ A randomized Phase III study of doxorubicin versus cisplatin/interferon alpha-2b/doxorubicin/ fluorouracil (PIAF) showed modest overall improvements in overall response rate and median survival with PIAF. However, the results were not statistically significant, and treatment-related toxicity was observed in patients receiving PIAF. ${ }^{13}$ Somewhat more promising data support the use of FOLFOX (infusional fluorouracil, leucovorin, and oxaliplatin) and GEMOX (gemcitabine-oxaliplatin). A Phase III trial involving 371 Asian patients with advanced HCC comparing modified FOLFOX and doxorubicin $\left(50 \mathrm{mg} / \mathrm{m}^{2}\right.$ every 3 weeks) showed improved PFS for FOLFOX (2.93 months vs 1.77 months; $\mathrm{HR}=0.62 ; 95 \% \mathrm{CI}=0.49-0.79 ; P<0.001)$. The primary endpoint of difference in OS was not met, but there was a trend toward improvement with FOLFOX $(\mathrm{HR}=0.79$; 95\% CI=0.63-0.99; $P=0.04)$. Proportions of grade 3 or 4 adverse events were similar between treatment groups. ${ }^{14}$ It is unclear whether these findings in patients with predominantly hepatitis B virus (HBV)-associated HCC can be extrapolated to American patients with predominantly HCV- and NAFLDassociated HCC.

A number of small, single arm trials suggest that GEMOX is a good option for advanced HCC. In a study, 21 patients with advanced $\mathrm{HCC}$ demonstrated an overall response rate of $19 \%(95 \% \mathrm{CI}=13 \%-26 \%)$, median PFS of 5 months, and median OS of 12 months. ${ }^{15}$ In another study, in 32 patients with previously untreated advanced $\mathrm{HCC}$, GEMOX produced 
a response rate of $18 \%(95 \% \mathrm{CI}=8 \%-34 \%)$, median PFS of 6.3 months, and OS of 11.5 months. For unclear reasons, treatment was significantly more effective in patients with nonalcoholic rather than alcoholic cirrhosis. ${ }^{16}$ In both trials, GEMOX was reasonably well tolerated.

A meta-analysis of 13 studies using first-line oxaliplatinbased chemotherapy demonstrated a pooled response rate of $16.8 \%$. The median PFS and OS were found to be 4.2 and 9.3 months, respectively, and the 1 -year OS was $37 \% .{ }^{17}$ As the majority of data on chemotherapy in HCC is from the first-line setting, there is substantial uncertainty regarding the tolerability of such an approach following sorafenib failure. However, for medically fit patients who have progressed on sorafenib and regorafenib and who are unable to participate in a clinical trial, we recommend the use of FOLFOX or GEMOX.

\section{Hormone therapies}

Several hormonal agents studied in HCC, including tamoxifen, megestrol, octreotide, and lanreotide, have failed to show meaningful clinical benefit in HCC. Due to the presence of estrogen receptors on one-third of $\mathrm{HCCs}$, estrogen receptor blockade with tamoxifen was hypothesized to have potential benefit in HCC. Four randomized controlled trials (RCTs) and a Cochrane systematic review of tamoxifen in HCC failed to show improvement with respect to survival or functional status. ${ }^{18-22}$ Data are conflicting regarding the use of megestrol in HCC. A small RCT comparing megestrol versus supportive care alone showed improved median OS with megestrol (18 months, 95\% CI=13.47-22.53 months) versus untreated patients ( 7 months, 95\% CI=3.01-10.99, $P=0.0090) .{ }^{23} \mathrm{How}-$ ever, a larger randomized placebo-controlled trial involving 204 patients with treatment-naive advanced HCC showed no improvement in OS, and in fact showed worse outcomes amongst patients with poor performance status or Child Pugh class B or C who received megestrol. ${ }^{24}$ Somatostatin analogs, such as octreotide and lanreotide, have been studied in HCC and have shown some survival benefit in patients with positive octreotide scans ${ }^{25}$ but have failed to show consistent improvement with respect to PFS or OS. ${ }^{26-30}$ The balance of evidence suggests that hormone therapies are not effective against HCC and should not be considered part of clinical practice.

\section{Molecularly targeted therapies}

Since sorafenib's approval, there have been multiple trials comparing first-line sorafenib to a novel targeted agent or combined with another agent that have failed to show any clinically relevant benefit over sorafenib. ${ }^{12,31-33}$ A variety of drugs have also failed to show benefit in the second-line setting. ${ }^{34-37}$ The two key exceptions are lenvantinib and regorafenib, both multi-target TKIs that have recently met their primary endpoints in first- and second-line therapy, respectively.

\section{Multi-targeted agents}

Regorafenib is an orally active nonspecific TKI that works by inhibiting several pro-neoplastic pathways, including those involved in angiogenesis, growth, and metastasis. In April 2017, the FDA approved regorafenib for second-line use in patients with HCC who were previously treated with sorafenib on the basis of the RESORCE trial, a randomized double-blind placebo controlled trial of the efficacy of regorafenib in advanced, refractory HCC. ${ }^{38,39}$ This study of 573 patients with ECOG PS 0-1 and Child Pugh A cirrhosis whose tumors had progressed after receiving sorafenib demonstrated a median OS of 10.6 months with regorafenib versus 7.8 months with placebo $(\mathrm{HR}=0.63 ; 95 \% \mathrm{CI}=0.50-0.79$; one-sided $P<0.0001)$. The median PFS was found to be 3.1 months with regorafenib versus 1.5 months with placebo. The profile of clinically relevant adverse events were as expected from regorafenib including hypertension ( $15 \%$ in regorafenib group versus $5 \%$ in placebo group), hand-foot syndrome ( $13 \%$ versus $1 \%$ ), fatigue ( $9 \%$ versus $5 \%$ ), and diarrhea $(3 \%$ versus $0 \%$ ). The recommended dose of regorafenib is 160 mg once daily on days $1-21$ of a 28 -day cycle. ${ }^{39}$ This is the first new FDA-approved drug for HCC in more than a decade and represents the only FDA-approved drug for second-line treatment of HCC.

Lenvatinib, another oral multikinase inhibitor that targets VEGFR, FGFR, PDGFR-beta, RET, and KIT, demonstrated similar activity as sorafenib as a first-line treatment for advanced HCC. ${ }^{40}$ In the open-label REFLECT study, 954 patients with untreated HCC were randomized to receive lenvatinib or sorafenib as initial therapy. The trial met its primary endpoint, showing lenvatinib to be noninferior to sorafenib (median OS 13.6 vs 12.3 months, $H R=0.92$, 95\% CI=0.79-1.06). Median PFS was better in lenvatinibtreated patients $(7.4$ months vs 3.7 months, $\mathrm{HR}=0.66,95 \%$ $\mathrm{CI}=0.57-0.77$ ), as was the disease control rate of $71.7 \%$ versus $60.5 \%$. Lenvatinib did not, however, have a better adverse effect profile. Patients reported similar declines in health-related quality of life after treatment initiation in both groups and similar rates of severe toxicities. ${ }^{40}$

\section{Hepatocyte growth factor/MET inhibitors}

The mesenchymal-epithelial transition (MET) factor receptor is dysregulated in HCC. Tivantinib is a selective oral MET 
inhibitor with a tolerable safety profile that demonstrated initial efficacy against $\mathrm{HCC}$ in tumors with high MET expression. ${ }^{37,41}$ Unfortunately, in the randomized, placebocontrolled METIV-HCC Phase III trial, tivantinib did not improve PFS or OS as second-line therapy for patients with MET high HCC. ${ }^{42}$

\section{Anti-VEGF therapies}

Given the highly vascular nature of HCC and high levels of VEGF expression, multiple other agents that target the VEGF pathway have been evaluated in HCC. These agents consistently demonstrate some clinical activity, but fewer patients seem to derive benefit from drugs targeting VEGF alone compared to VEGF pathway inhibitors used in combination with other targets.

Bevacizumab, an anti-VEGF monoclonal antibody, has shown activity as a single agent and in combination with other drugs in HCC. A small Phase II study of bevacizumab in 46 patients with liver-confined $\mathrm{HCC}$, good performance status and compensated liver disease demonstrated a PFS of $65 \%$ at 6 months and objective response in six patients (13\%; 95\% CI=3\%-23\%). Median PFS time was found to be 6.9 months (95\% CI, 6.5-9.1 months), and OS was found to be $53 \%$ at 1 year, $28 \%$ at 2 years, and $23 \%$ at 3 years. The most commonly recorded clinically significant adverse events included hypertension, thrombosis, and hemorrhage, including one fatal variceal bleed. ${ }^{43}$

Bevacizumab has also been studied in combination with other therapies. A small Phase II trial combining bevacizumab with GEMOX showed a median OS of 9.6 months and median PFS of 5.3 months. The most common treatment-related grade 3 to 4 toxicities recorded were leukopenia/neutropenia, transient elevation of aminotransferases, hypertension, and fatigue. ${ }^{44}$ While this study demonstrated the safety and efficacy of the combination of bevacizumab and GEMOX, it is unclear whether the combination is better than bevacizumab or GEMOX given alone. Another Phase II trial combining bevacizumab with oxaliplatin and capecitabine showed a median PFS of 6.8 months and median OS of 9.8 months. Eight patients (20\%) achieved partial response and 23 patients $(58 \%)$ had stable disease, conferring an overall disease control rate of $77.5 \%$. The combination therapy was generally well tolerated with limited grade $3 / 4$ toxicity recorded; the toxicities were mainly peripheral neurotoxicity and fatigue. ${ }^{45} \mathrm{~A}$ Phase II study of bevacizumab with erlotinib showed a median time to progression of 3.9 months and median OS of 9.9 months. ${ }^{46}$ The consensus of the National Comprehensive
Cancer Network (NCCN) at this time is that there are insufficient data to support the use of bevacizumab in patients with $\mathrm{HCC}^{6}$

Sunitinib, another nonspecific TKI which targets the VEGFRs amongst other pathways, failed to show significant efficacy in HCC. A large, randomized Phase III study comparing sunitinib and sorafenib was terminated early for futility and safety reasons. ${ }^{31}$ Axitinib, a second-generation TKI that targets VEGFRs, has been studied in a randomized Phase II trial of patients with advanced HCC with progression or intolerance of sorafenib. This study compared best supportive care plus axitinib versus placebo, and found no significant difference in median OS. ${ }^{47}$

Ramucirumab is a recombinant monoclonal antibody that inhibits the VEGFR. A Phase III trial of patients previously treated with sorafenib failed to show significant improvement in OS over placebo (9.2 versus 7.6 months; $\mathrm{HR}=0.87$, 95\% $\mathrm{CI}=0.72-1.05 ; P=0.14)$, but it did show improvement in median PFS (2.8 versus 2.1 months; $\mathrm{HR}=0.63,95 \%$ $\mathrm{CI}=0.52-0.75 ; P<0.001)$ and time to tumor progression $(3.5$ versus 2.6 months; $\mathrm{HR}=0.59 ; 95 \% \mathrm{CI}=0.49-0.72 ; P<0.001)$. Unplanned subset analysis suggested the potential for a survival benefit in patients with a high initial level of alphafetoprotein (AFP, $>400 \mathrm{ng} / \mathrm{mL}$ ) at diagnosis, ${ }^{34}$ and a follow-up Phase III study among patients with elevated baseline AFP is currently underway (NCT02435433).

\section{Anti-EGFR therapies}

Epidermal growth factor receptor (EGFR) and ligand expression is frequently seen in HCC; however, neither EGFR TKIs nor monoclonal antibodies have demonstrated benefit against HCC. Erlotinib, an oral TKI with specificity for EGFR, offers some modest control over HCC as demonstrated in two Phase II studies investigating first-line use of the drug. ${ }^{48,49}$ Its efficacy in combination with bevacizumab has been studied with conflicting results. ${ }^{50,51}$ In an ongoing randomized Phase II trial, investigators are studying how bevacizumab in combination in comparison to sorafenib as the first-line therapy (NCT00881751). Erlotinib combined with sorafenib was assessed in a randomized Phase III trial and showed no significant improvement in OS compared to sorafenib with placebo. In addition, in patients receiving erlotinib and sorafenib, the disease control rate was significantly lower (43.9\% versus $52.5 \% ; P=0.021) .{ }^{33}$

When studied in a Phase II trial, cetuximab, a chimeric monoclonal antibody that binds specifically to EGFR, was generally well tolerated but showed no antitumor activity in HCC. ${ }^{52}$ Cetuximab has been combined with capecitabine and 
oxaliplatin $^{53}$ and GEMOX ${ }^{54}$ in single arm Phase II trials with disappointing results.

\section{Other targeted therapies}

The mechanistic target of rapamycin (mTOR) is a central regulator of cell growth and angiogenesis, and the mTOR pathway is activated in $40 \%-50 \%$ of the patients with HCC. ${ }^{55}$ Based on early promise in the Phase II setting, everolimus (an mTOR inhibitor) was studied in a large Phase III trial of patients with progression or intolerance to sorafenib. This study showed no improvement in OS over placebo. ${ }^{36}$

Fibroblast growth factor (FGF) proteins are involved in tumor growth and angiogenesis in HCC and are thought to play a role in relapse with sorafenib through evasion of VEGF blockade. Brivanib is a selective dual inhibitor of FGF and VEGF receptor tyrosine kinases. The Phase III BRISK-PS trial evaluated the efficacy and safety of brivanib in patients with advanced HCC who had intolerance to or progression on or after sorafenib. Brivanib did not significantly improve median OS compared to placebo (9.4 versus 8.2 months, $\mathrm{HR}=0.89 ; 95.8 \% \mathrm{CI}=0.69-1.15 ; P=0.3307) .{ }^{35}$ Other studies are underway to determine whether FGF receptor inhibitors have greater efficacy in selected patients with FGF amplification (NCT02421185, NCT02508467, and NCT03144661).

\section{Immunotherapy}

Without a doubt, immuno-oncology is the most exciting new therapeutic arena in HCC. There is a substantial body of evidence that supports the rationale for the use of immune-based approaches to treat $\mathrm{HCC} .{ }^{56}$ This theoretical rationale is now supported by evidence that multiple checkpoint inhibitors are active in advanced HCC.

Some of the earliest data on immunotherapy came from a Phase II study of the CTLA-4 inhibitor tremelimumab in patients with chronic $\mathrm{HCV}$ and advanced HCC. In this small study, tremelimumab resulted in a response rate of $18 \%$, a disease control rate of $76 \%$, and a median OS of 8.2 months. ${ }^{57}$ More recently, the large Phase I/II CheckMate 040 study of nivolumab, a human monoclonal antibody inhibitor of programmed death-1 (PD-1), has shown that nivolumab has robust activity in advanced HCC. This study included 262 patients with unselected PD-L1 tumors-both treatment naïve patients and those who had received one prior line of therapy, usually sorafenib. Following confirmation of safety and tolerability in the dose-escalation phase, all patients in the dose-expansion phase received intrave- nous nivolumab $3 \mathrm{mg} / \mathrm{kg}$ every 2 weeks until disease progression or limiting toxicity. The overall objective response rate was $15 \%(95 \% \mathrm{CI}=6-28)$ in the dose-escalation phase, including three complete responses and four partial responses, and 20\% $(95 \% \mathrm{CI}=15-26)$ in patients treated with nivolumab $3 \mathrm{mg} / \mathrm{kg}$ in the dose-expansion phase. Notably, responses were observed regardless of PD-L1 expression on tumor cells, and typically occurred within 3 months of treatment initiation. Median OS was found to be 28.8 months in the sorafenib naïve group, and 15.6 months in the sorafenib-treated group. ${ }^{58}$ The most common grade 3 or 4 treatment-related adverse events consisted of increased levels of aspartate aminotransferase (4\%) and alanine aminotransferase $(2 \%)$, without any evidence of clinical repercussions. Symptomatic treatment-related adverse events were comparable in patients with and without viral hepatitis infection. ${ }^{58}$ The Phase III CheckMate 459 trial is currently underway and aims to compare nivolumab and sorafenib as first-line therapy in patients with advanced HCC (NCT02576509).

In addition to nivolumab, multiple other immune checkpoint inhibitors are being evaluated in HCC. For example, durvalumab (anti-PDL1) has shown comparable response rates and duration of disease control as nivolumab in a small Phase I/II trial. ${ }^{59}$ The Phase III KEYNOTE-240 study is an ongoing randomized, double blind, placebo controlled study of pembrolizumab versus placebo in patients with sorafenib refractory/intolerance advanced HCC (NCT02702401). Combination CTLA-4 and PD-1/PDL-1 inhibitor trials are also ongoing with durvalumab/tremelimumab (NCT02519348) as well as nivolumab/ipilimumab (Checkmate 040, NCT01658878).

\section{Challenges and opportunities for treatment of $\mathrm{HCC}$}

$\mathrm{HCC}$ remains one of the leading causes of cancer-related deaths around the world, and there is an unmet need for systemic therapies to effectively and safely treat patients with this cancer. While we are beginning to see some promise of improved therapeutic options (summarized in Table 2), a great need for further investigation exists. We strongly encourage all patients with advanced HCC to participate in clinical trials. The complexity of this disease underscores the importance of a multidisciplinary clinical approach and a multi-faceted research approach encompassing clinical providers, clinical and basic science researchers, and public health leaders. While optimal therapy for second-line treatment of HCC remains unclear, we anticipate promising 
therapies on the horizon that will only be possible through the willing participation of both patients and providers in investigation of new therapies.

\section{Disclosure}

The authors report no conflicts of interest in this work.

\section{References}

1. Choo SP, Tan WL, Goh BK, Tai WM, Zhu AX. Comparison of hepatocellular carcinoma in Eastern versus Western populations. Cancer. 2016;122(22):3430-3446.

2. National Health and Nutrition Examination Survey - Viral Health: Department of health and human services. Centers for disease control and prevention. National center for health statistics. Available from: https://www.cdc.gov/nchs/data/nhanes/databriefs/viralhep.pdf. Accessed May 4, 2017.

3. Heimbach J, Kulik LM, Finn R, et al. AASLD guidelines for the treatment of hepatocellular carcinoma. 2016 December. Available from: https://www.aasld.org/sites/default/files/guideline_documents/ Heimbach_et_al-2017-Hepatology.pdf. Accessed May 4, 2017.

4. Makarova-Rusher OV, Altekruse SF, McNeel TS, et al. Population attributable fractions of risk factors for hepatocellular carcinoma in the United States. Cancer. 2016;122(11):1757-1765.

5. Llovet JM, Burroughs A, Bruix J. Hepatocellular carcinoma. Lancet. 2003;362(9399):1907-1917.

6. National Comprehensive Cancer Network. Hepatobiliary cancers (version 1.2017). Available from: https://www.nccn.org/professionals/ physician_gls/pdf/hepatobiliary.pdf. Accessed May 4, 2017.

7. Llovet JM, Ricci S, Mazzaferro V, et al; SHARP Investigators Study Group. Sorafenib in advanced hepatocellular carcinoma. N Engl J Med. 2008;359(4):378-390.

8. Zhu YJ, Zheng B, Wang HY, Chen L. New knowledge of the mechanisms of sorafenib resistance in liver cancer. Acta Pharmacol Sin. 2017;38(5):614-622.

9. Gallupo RR, Ramaiah D, Ponte OM, Gedaly R. Molecular therapies in hepatocellular carcinoma: what can we target? Dig Dis Sci. 2014;59(8):1688-1697.

10. Zehir A, Benayed R, Shah RH, et al. Mutational landscape of metastatic cancer revealed from prospective clinical sequencing of 10,000 patients. Nat Med. 2017;23(6):703-713.

11. Varghese AM, Berger MF. Advancing clinical oncology through genome biology and technology. Genome Biol. 2014;15(8):427.

12. Abou-Alfa GK, Niedzwieski D, Knox JJ, et al. Phase III randomized study of sorafenib plus doxorubicin versus sorafenib in patients with advanced hepatocellular carcinoma (HCC): CALGB 80802 (Alliance). Proceedings of the Gastrointestinal Cancers Symposium, San Francisco, CA, 22 January 2016. USA.

13. Yeo W, Mok TS, Zee B, et al. A randomized phase III study of doxorubicin versus cisplatin/interferon alpha-2b/doxorubicin/fluorouracil (PIAF) combination chemotherapy for unresectable hepatocellular carcinoma. J Natl Cancer Inst. 2005;97(20):1532-1538.

14. Qin S, Bai Y, Lim HY, et al. Randomized, multicenter, open-label study of oxaliplatin plus fluorouracil/leucovorin versus doxorubicin as palliative chemotherapy in patients with advanced hepatocellular carcinoma from Asia. J Clin Oncol. 2013;31(28):3501-3508.

15. Taïeb J, Bonyhay L, Golli L, et al. Gemcitabine plus oxaliplatin for patients with advanced hepatocellular carcinoma using two different schedules. Cancer. 2003;98(12):2664-2670.

16. Louafi S, Boige V, Ducreux M, et al. Gemcitabine plus oxaliplatin (GEMOX) in patients with advanced hepatocellular carcinoma (HCC): results of a phase II study. Cancer. 2007;109(7):1384-1390.

17. Petrelli F, Coinu A, Borgonovo K, et al. Oxaliplatin-based chemotherapy: a new option in advanced hepatocellular carcinoma. A systematic review and pooled analysis. Clin Oncol (R Coll Radiol). 2014;26(8): 488-496.
18. Castells A, Bruix J, Brú C, et al. Treatment of hepatocellular carcinoma with tamoxifen: a double-blind placebo-controlled trial in 120 patients. Gastroenterology. 1995;109(3):917-922.

19. Tamoxifen in treatment of hepatocellular carcinoma: a randomised controlled trial. CLIP Group (Cancer of the Liver Italian Programme). Lancet. 1998;352(9121):17-20.

20. Chow PK, Tai BC, Tan CK, et al; Asian-Pacific Hepatocellular Carcinoma Trials Group. High-dose tamoxifen in the treatment of inoperable hepatocellular carcinoma: a multicenter randomized controlled trial. Hepatology. 2002;36(5):1221-1226.

21. Nowak A, Findlay M, Culjak G, Stockler M. Tamoxifen for hepatocellular carcinoma. Cochrane Database Syst Rev. 2004;(3):CD001024.

22. Barbare JC, Bouché O, Bonnetain F, et al. Randomized controlled trial of tamoxifen in advanced hepatocellular carcinoma. J Clin Oncol. 2005;23(19):4338-4346.

23. Villa E, Ferretti I, Grottola A, et al. Hormonal therapy with megestrol in inoperable hepatocellular carcinoma characterized by variant oestrogen receptors. Br J Cancer. 2001;84(7):881-885.

24. Chow PK, Machin D, Chen Y, et al; Asia-Pacific Hepatocellular Carcinoma Trials Group. Randomised double-blind trial of megestrol acetate vs placebo in treatment-naive advanced hepatocellular carcinoma. $\mathrm{Br}$ Cancer. 2011;105(7):945-952.

25. Dimitroulopoulos D, Xinopoulos D, Tsamakidis K, et al. Long acting octreotide in the treatment of advanced hepatocellular cancer and overexpression of somatostatin receptors: randomized placebo-controlled trial. World J Gastroenterol. 2007;13(23):3164-3170.

26. Kouroumalis E, Skordilis P, Thermos K, Vasilaki A, Moschandrea J, Manousos ON. Treatment of hepatocellular carcinoma with octreotide: a randomised controlled study. Gut. 1998;42(3):442-447.

27. Yuen MF, Poon RT, Lai CL, et al. A randomized placebo-controlled study of long-acting octreotide for the treatment of advanced hepatocellular carcinoma. Hepatology. 2002;36(3):687-691.

28. Becker G, Allgaier HP, Olschewski M, Zähringer A, Blum HE; HECTOR Study Group. Long-acting octreotide versus placebo for treatment of advanced HCC: a randomized controlled double-blind study. Hepatology. 2007;45(1):9-15.

29. Raderer M, Hejna MH, Muller C, et al. Treatment of hepatocellular cancer with the long acting somatostatin analog lanreotide in vitro and in vivo. Int J Oncol. 2000;16(6):1197-1201.

30. Barbare JC, Bouché O, Bonnetain F, et al. Treatment of advanced hepatocellular carcinoma with long-acting octreotide: a phase III multicentre, randomised, double blind placebo-controlled study. Eur $J$ Cancer. 2009;45(10):1788-1797.

31. Cheng AL, Kang YK, Lin DY, et al. Sunitinib versus sorafenib in advanced hepatocellular cancer: results of a randomized phase III trial. J Clin Oncol. 2013;31(32):4067-4075.

32. Cainap C, Qin S, Huang WT, et al. Linifanib versus Sorafenib in patients with advanced hepatocellular carcinoma: results of a randomized phase III trial. J Clin Oncol. 2015;33(2):172-179.

33. Zhu AX, Rosmorduc O, Evans TR, et al. SEARCH: a phase III, randomized, double-blind, placebo-controlled trial of sorafenib plus erlotinib in patients with advanced hepatocellular carcinoma. J Clin Oncol. 2015;33(6):559-566.

34. Zhu AX, Park JO, Ryoo BY, et al; REACH Trial Investigators. Ramucirumab versus placebo as second-line treatment in patients with advanced hepatocellular carcinoma following first-line therapy with sorafenib (REACH): a randomised, double-blind, multicentre, phase 3 trial. Lancet Oncol. 2015;16(7):859-870.

35. Llovet JM, Decaens T, Raoul JL, et al. Brivanib in patients with advanced hepatocellular carcinoma who were intolerant to sorafenib or for whom sorafenib failed: results from the randomized phase III BRISK-PS study. J Clin Oncol. 2013;31(28):3509-3516.

36. Zhu AX, Kudo M, Assenat E, et al. Effect of everolimus on survival in advanced hepatocellular carcinoma after failure of sorafenib: the EVOLVE-1 randomized clinical trial. JAMA. 2014;312(1):57-67.

37. Santoro A, Rimassa L, Borbath I, et al. Tivantinib for second-line treatment of advanced hepatocellular carcinoma: a randomised, placebocontrolled phase 2 study. Lancet Oncol. 2013;14(1):55-63. 
38. The ASCO Post. FDA expands approved use of regorafenib for hepatocellular carcinoma. 2017 Apr 27. Available from: http://www.ascopost. com/News/55555. Accessed April 28, 2017.

39. Bruix J, Qin S, Merle P, et al; RESORCE Investigators. Regorafenib for patients with hepatocellular carcinoma who progressed on sorafenib treatment (RESORCE): a randomised, double-blind, placebo-controlled, phase 3 trial. Lancet. 2017;389(10064):56-66.

40. Cheng AL, Finn RS, Qin S, et al. A phase III trial of lenvatinib (LEN) vs sorafenib (SOR) in first-line treatment of patients with unresectable hepatocellular carcinoma (REFLECT study). J Clin Oncol. 2017;35(Suppl; abstr: 4001).

41. Santoro A, Simonelli M, Rodriguez-Lope C, et al. A Phase-1b study of tivantinib (ARQ 197) in adult patients with hepatocellular carcinoma and cirrhosis. Br J Cancer. 2013;108(1):21-24

42. Rimassa L, Assenat E, Peck-Radosavljevic M, et al. Second-line tivantinib (ARQ 197) vs placebo in patients (Pts) with MET-high hepatocellular carcinoma (HCC): Results of the METIV-HCC phase III trial. $J$ Clin Oncol. 2017;35(Suppl; abstr: 4000).

43. Siegel AB, Cohen EI, Ocean A, et al. Phase II trial evaluating the clinical and biologic effects of bevacizumab in unresectable hepatocellular carcinoma. J Clin Oncol. 2008;26(18):2992-2998.

44. Zhu AX, Blaszkowsky LS, Ryan DP, et al. Phase II study of gemcitabine and oxaliplatin in combination with bevacizumab in patients with advanced hepatocellular carcinoma. J Clin Oncol. 2006;24(12): 1898-1903.

45. Sun W, Sohal D, Haller DG, et al. Phase 2 trial of bevacizumab, capecitabine, and oxaliplatin in treatment of advanced hepatocellular carcinoma. Cancer. 2011;117(14):3187-3192.

46. Kaseb AO, Morris JS, Iwasaki M, et al. Phase II trial of bevacizumab and erlotinib as second-line therapy for advanced hepatocellular carcinoma. Onco Targets Ther. 2016;9:773-780.

47. Kang YK, Yau T, Park JW, et al. Randomized phase II study of axitinib versus placebo plus best supportive care in second-line treatment of advanced hepatocellular carcinoma. Ann Oncol. 2015;26(12): 2457-2463.

48. Philip PA, Mahoney MR, Allmer C, et al. Phase II study of Erlotinib (OSI-774) in patients with advanced hepatocellular cancer. J Clin Oncol. 2005;23(27):6657-6663.
49. Thomas MB, Chadha R, Glover K, et al. Phase 2 study of erlotinib in patients with unresectable hepatocellular carcinoma. Cancer. 2007;110(5):1059-1067.

50. Kaseb AO, Garrett-Mayer E, Morris JS, et al. Efficacy of bevacizumab plus erlotinib for advanced hepatocellular carcinoma and predictors of outcome: final results of a phase II trial. Oncology. 2012;82(2): 67-74.

51. Philip PA, Mahoney MR, Holen KD, et al. Phase 2 study of bevacizumab plus erlotinib in patients with advanced hepatocellular cancer. Cancer. 2012;118(9):2424-2430.

52. Zhu AX, Stuart K, Blaszkowsky LS, et al. Phase 2 study of cetuximab in patients with advanced hepatocellular carcinoma. Cancer. 2007;110(3):581-589.

53. Sanoff HK, Bernard S, Goldberg RM, et al. Phase II study of capecitabine, oxaliplatin, and cetuximab for advanced hepatocellular carcinoma. Gastrointest Cancer Res. 2011;4(3):78-83.

54. Asnacios A, Fartoux L, Romano O, et al. Gemcitabine plus oxaliplatin (GEMOX) combined with cetuximab in patients with progressive advanced stage hepatocellular carcinoma: results of a multicenter phase 2 study. Cancer. 2008;112(12):2733-2739.

55. Treiber G. mTOR inhibitors for hepatocellular cancer: a forward-moving target. Expert Rev Anticancer Ther. 2009;9(2):247-261.

56. El-Khoueiry A. The promise of immunotherapy in the treatment of hepatocellular carcinoma. Am Soc Clin Oncol Educ Book. 2017;37: 311-317.

57. Sangro B, Gomez-Martin C, de la Mata M, et al. A clinical trial of CTLA-4 blockade with tremelimumab in patients with hepatocellular carcinoma and chronic hepatitis C. J Hepatol. 2013;59(1):81-88.

58. El-Khoueiry AB, Sangro B, Yau T, et al. Nivolumab in patients with advanced hepatocellular carcinoma (CheckMate 040): an open-label, non-comparative, phase 1/2 dose escalation and expansion trial. Lancet. 2017;389(10088):2492-2502.

59. Wainberg ZA, Segal NH, Jaeger D, et al. Safety and clinical activity of durvalumab monotherapy in patients with hepatocellular carcinoma (HCC). J Clin Oncol. 2017;35(Suppl; abstr: 4071).

60. Johnson PJ, Qin S, Park JW et al. Brivanib versus sorafenib as firstline therapy in patients with advanced hepatocellular carcinoma. J Clin Oncol. 2013;31(28):3517-3524.
Journal of Hepatocellular Carcinoma

\section{Publish your work in this journal}

The Journal of Hepatocellular Carcinoma is an international, peerreviewed, open access journal that offers a platform for the dissemination and study of clinical, translational and basic research findings in this rapidly developing field. Development in areas including, but not limited to, epidemiology, vaccination, hepatitis therapy, pathology and

\section{Dovepress}

molecular tumor classification and prognostication are all considered for publication. The manuscript management system is completely online and includes a very quick and fair peer-review system, which is all easy to use. Visit http://www.dovepress.com/testimonials.php to read real quotes from published authors. 